\title{
Section V
}

\section{The Cometary Coma}




\title{
THE COMPOSITION OF COMETS ${ }^{1}$
}

\author{
DIETER KRANKOWSKY \\ Max-Planck-Institut für Kernphysik \\ P.O. Box 103 980, 6900 Heidelberg, FRG
}

\begin{abstract}
The chemical composition of gases in the coma of Comet Halley obtained from in situ and remote observations is reviewed. Water vapor with an abundance of approximately $80 \%$ by number is the dominant parent gas. Carbon monoxide is the second most abundant molecule, with about one-seventh of the water abundance. The other expected parent gasescarbon dioxide, methane, and ammonia-contributed with at most a few percent to the coma gas. Molecular nitrogen is found to be a minor species, with an abundance of less than one percent. Formaldehyde is relatively abundant, with a few percent relative to water. Gas-phase isotope ratios of nitrogen, oxygen, and sulfur are found to agree with solar system values within experimental errors. Halley's hydrogen isotope ratio is comparable to the values found in other solar system objects poor in hydrogen, but distinctly different from the protosolar nebula and objects that accreted hydrogen in gaseous form. Carbon in the cyanide radical is enriched by $35 \%$ in ${ }^{13} \mathrm{C}$ compared to the bulk solar system value that indicates the presence of non-homogenized interstellar carbon in Halley. Volatiles released from grains contribute noticeably to the coma gas. Complex organic molecules, inferred from various observations as constituents of the dust grains, are believed to be the origin of the distributed $\mathrm{CO}$ source, $\mathrm{CN}$, and other jet structures in the coma.
\end{abstract}

\section{Introduction}

The missions of five spacecraft to Comet Halley in 1986 (Nature, 321, 1986) for the first time allowed a close-up view into and in situ measurements of the inner coma of a comet. Together with a wealth of Earth-bound and near-Earth-based observations, these measurements covered the entire range of the electromagnetic spectrum from the farultraviolet to radar wavelengths, providing the most complete set so far of compositional data of cometary volatiles and the only information on chemical properties of the dust obtained for an individual comet ${ }^{2}$. Before, only Comet Kohoutek (1973 XII) was studied in a coordinated observational program, although the nine-month time for preparation did not allow for anything comparable to the Halley program. Furthermore, instrumental techniques, detectors, and space vehicles have since become mature and now permit observation of the coma at infrared and radio wavelengths.

Spectra in the visible (Arpigny et al. 1990), studied for decades, show the resonance fluorescence of sunlight by radicals and yield information on species like $\mathrm{CN}, \mathrm{NH}, \mathrm{NH}_{2}, \mathrm{C}_{2}$, and $\mathrm{C}_{3}$. Their parent molecules constitute only a minute fraction of the volatile component

\footnotetext{
${ }^{1}$ This article is an updated version of a contribution by Krankowsky and Eberhardt to the book $C O M E T$ HALLEY-Investigations, Results, and Interpretations, ed. J. Mason, Ellis Horwood Ltd., Chichester, England, 1990.

${ }^{2}$ Early results have been presented on two conferences: Exploration of Halley's Comet, eds. B. Battrick, E.J. Rolfe, and R. Reinhard, ESA SP-250, 3 vols., 1986, and Diversity and Similarity of Comets, eds. E.J. Rolfe and B. Battrick, ESA SP-278, 1987.
} 
of comets. Since the early 1970 s, when ultraviolet (UV) spectroscopy of cometary comae from space vehicles started, the major volatile constituents of very many comets have been observed. The presumed dominant water is detectable by its dissociation products $\mathrm{H}, \mathrm{O}$, and $\mathrm{OH}$. Carbon monoxide and its ion are detected directly, while carbon dioxide can only be observed through its metastable $\mathrm{CO}$ dissociation product or indirectly through the ion $\mathrm{CO}_{2}^{+}$. Other almost omnipresent signatures in the ultraviolet spectra are due to $\mathrm{C}, \mathrm{S}$, and CS. Major contributions to the UV spectroscopy of comets have been made by the International Ultraviolet Explorer (IUE) satellite, which obtained spectra of more than 30 comets (Feldman 1990). Although these comets have been very different with respect to their gas/dust ratio, gas production rate, and heliocentric distance and have been observed at different geometries, their ultraviolet spectra appear to be rather similar. Thus it has been argued (Feldman 1982, 1990) that the ultraviolet spectra suggest a common chemical composition and perhaps common origin of comets. Most of the parent progenitors of the atoms, radicals, and ions detected in the visible and ultraviolet spectra have no strong electronic transitions at these wavelengths. Parent molecules can only be observed in their vibrational transitions in the near and medium infrared or in their rotational transitions at far infrared and microwave wavelengths (Weaver et al. 1990). The rapid development in radio astronomy has added another important spectral window for the search for parent molecules (Crovisier and Schloerb 1990).

The following sections will concentrate on the chemical composition of the volatile component as observed in Halley. In a recent article by Whipple (1989), in which the developments in cometary science within the last thirty years are outlined, a modern bibliography on the subject can be found.

\section{Coma Composition and Parent Molecules}

The chemical composition of the gas in the coma is different from the composition of the volatiles in the nucleus. Photoprocesses, as well as the chemical reactions between neutrals, and between neutrals and ions, can lead to substantial alterations of the molecular composition of the expanding gas in the coma. Expansion velocities are typically on the order of $1 \mathrm{~km} / \mathrm{s}$, and hence a molecule takes 3 hours to reach a distance of $10,000 \mathrm{~km}$. For some species, lifetimes against photodissociation are much shorter. Spectroscopic composition measurements, depending on the strength of the investigated lines, often cover a substantial radial range. It is then necessary to make appropriate corrections for the change in the chemistry occurring in this distance range, in order to obtain the composition at the nuclear surface. These corrections are facilitated if radial profiles can be obtained which can be fitted to the theoretical models, such as the Haser model (Haser 1957, 1966), or the more sophisticated vectorial model (Combi and Delsemme 1980, Festou 1981). Measurements closer to the nucleus than $10^{4} \mathrm{~km}$ are difficult, however, and the radial resolution obtainable is often only a few thousand kilometers.

In situ neutral mass spectrometer (NMS) measurements on board Giotto, which made the closest approach to Halley's nucleus, were obtained to a distance of $\sim 1,000 \mathrm{~km}$ from the nucleus. Still, at such a far range, very reactive molecules or species with a lifetime much smaller than $1,000 \mathrm{~s}$ were not observable by the instruments. This limitation can cause considerable uncertainty in deducing the chemical composition at the nucleus from the measurements in the coma. For instance, from the in situ measurements, it will probably not be possible to decide whether $S_{2}$ (lifetime $\approx 350 \mathrm{~s}$ ), discovered by A'Hearn et al. (1983) 
in Comet IRAS-Araki-Alcock (1983 VII), is a possible precursor of the relatively abundant neutral and the ionized sulfur observed by the Giotto instruments.

\subsection{WATER VAPOR}

Water has been expected to be the major volatile species, because its dissociation products dominate the ultraviolet spectra of comets. But unquestioned direct observation before Halley was not available. The tentative identification of water in Comet Bradfield (1974 III) by its $1.35-\mathrm{cm}$ line at radio wavelengths by Jackson et al. (1976) was challenged by Crovisier et al. (1981) and by Hollis et al. (1981). Searches for the $1.35-\mathrm{cm}$ line in other comets gave negative results, except for Comet IRAS-Araki-Alcock (1983 VII), where apparently this line was detected by Altenhoff et al. (1983). Similarly, efforts to identify water ice were not conclusive. Reports of the detection of $\mathrm{H}_{2} \mathrm{O}$ absorption at $3 \mu \mathrm{m}$ (Campins et al. 1983, Hanner 1984) were questioned by A'Hearn et al. (1984). However, observational evidence for water ice in Comet Kohoutek (1973 XII) and in Comet P/Schwassmann-Wachmann 1 was claimed by Crifo (1983) and Hartmann and Cruikshank (1983), respectively.

The first definite detection of water vapor in a comet by remote observation was achieved on December 22 and 24, 1985 (Mumma et al. 1986), when nine infrared spectral lines of the $\nu_{3}$ band $(2.65 \mu \mathrm{m})$ were found in the coma of Halley's Comet by a Fourier transform spectrometer on board the NASA-Kuiper Airborne Observatory. From these data and later observations, production rates, spatial distribution, and outflow velocities of $\mathrm{H}_{2} \mathrm{O}$ were derived (Weaver et al. 1986). Water was also detected by the infrared spectrometer (IKS) on the VEGA 1 spacecraft (Combes et al. 1986, 1988) on March 6 by observing the $\nu_{3}$ band at $2.65 \mu \mathrm{m}$ and from the three-channel spectrometer (TKS) on VEGA 2 (Krasnopolsky et al. 1986) on March 9 by utilizing the $1.38-\mu \mathrm{m}$ band. The first in situ measurement of water vapor in a cometary coma was obtained from the NMS experiment on board the European Space Agency's Giotto spacecraft on March 13, 1986, when it flew past the nucleus of Halley's Comet at a distance of about $600 \mathrm{~km}$ (Krankowsky et al. 1986). These data established that $\mathrm{H}_{2} \mathrm{O}$ is the most abundant volatile, with $80 \%$ by number.

The IUE satellite observatory provided monitoring of the water production of $\mathrm{Hal}$ ley during the period from September 1985 to July 1986, except for a two-month period between January and March, when the solar elongation angle to the comet was too small. The $\mathrm{H}_{2} \mathrm{O}$ gas production rates as a function of the heliocentric distance of Halley were retrieved from the fluorescent emission of $\mathrm{OH}$ (0-0 band) from IUE data (Festou et al. 1986, Feldman et al. 1986b). Pre- and post-perihelion observations of the $\mathrm{OH}$ emission are also available from the Soviet ASTRON satellite (Boyarchuk et al. 1987). These data are complemented by the production rates obtained from the H I Lyman- $\alpha$ measurements of the Pioneer Venus Orbiter ultraviolet spectrometer (Stewart 1987) and the Dynamics Explorer-1 satellite (Craven and Frank 1987). The water production rates from the various observations are in reasonable agreement.

From the Lyman- $\alpha$ measurements, obtained by the ultraviolet imager on board the Suisei spacecraft, a periodic breathing of the hydrogen coma has been derived by Kaneda et al. (1986). Outbursts of water from the surface has been suggested by the authors as the possible cause. The Suisei data have been criticized by Feldman (1990), who pointed out that the rapid time variability is not confirmed by the Lyman- $\alpha$ observations by IUE. 


\subsection{CARBON MONOXIDE}

The second most abundant gas in the coma of Halley is $\mathrm{CO}$, as found by the in situ mass spectra of the NMS experiment on Giotto (Eberhardt et al. 1986a, 1987a). At distances between 20,000 and $50,000 \mathrm{~km}$, CO's abundance is $15 \%$ relative to water, dropping to $7 \%$ at a distance of $1,000 \mathrm{~km}$ from the nucleus. This can be understood in terms of an extended source of $\mathrm{CO}$ in the coma (Eberhardt et al. 1987a) contributing about half the amount of the measured $\mathrm{CO}$. Carbon monoxide was also measured by ultraviolet spectrometers on two sounding rockets (Woods et al. 1986) and verified as the second most abundant gas in Halley. On February 26, 1986, a relative abundance of $(20 \pm 5) \%$ was found. The data obtained on March 13,1986, gave a CO gas production rate relative to $\mathrm{H}_{2} \mathrm{O}$ of $(17 \pm 4) \%$ in very good agreement with the value from the NMS experiment, thus confirming the assumption that the 28-amu/e mass spectral peaks are mostly due to $\mathrm{CO}$. The radial brightness profiles from the rocket flights also seem to suggest the presence of a source of $\mathrm{CO}$ in addition to the nucleus. Marginal detections of $\mathrm{CO}$ were also reported by Combes et al. $(1986,1988)$ from the infrared experiment IKS aboard the VEGA 1 spacecraft and by Festou et al. (1986) from IUE observations, where estimates for CO gas production rates relative to $\mathrm{H}_{2} \mathrm{O}$ range from $10 \%$ to $20 \%$, in agreement with the Giotto and rocket results. In comparison, a $27 \% \mathrm{CO}$ abundance relative to $\mathrm{H}_{2} \mathrm{O}$ was found for Comet West (1976 VI) (Feldman and Brune 1976, Feldman 1978), whereas Comet Bradfield (1979 X) contained only $\sim 1 \%$ CO (Weaver 1981).

\subsection{CARBON DIOXIDE}

In $\mathrm{P} / \mathrm{Halley}$, carbon dioxide was detected for the first time in a comet, although the bands of $\mathrm{CO}_{2}^{+}$in ion tails of comets (Festou et al. 1982) have suggested its presence. The IKS instrument on VEGA 1 derived, in a first analysis of the $\nu_{3}$ band at $4.3 \mu \mathrm{m}$, an abundance of $1.5 \%$ relative to $\mathrm{H}_{2} \mathrm{O}$ (Combes et al. 1986), which was revised to $2 \%$ by Moroz et al. (1987). Most recently, Combes et al. (1988) obtained from the same data a $\mathrm{CO}_{2}$ abundance of $2.7 \%$ relative to water. From the radial density profile of the mass peak at $44 \mathrm{amu} / \mathrm{e}$, measured by the NMS experiment on Giotto, an upper limit of $3.5 \%$ relative to water was found, allowing for the possible contributions of other species such as CS and $\mathrm{C}_{3} \mathrm{H}_{8}$ to the 44-amu/e mass peak (Krankowsky et al. 1986). Carbon dioxide is abundant in comets. It contributes to the carbon inventory in the volatile fraction and, as suggested by Feldman et al. (1986a), could be responsible, due to its high volatility, for outbursts observed at large heliocentric distances.

\subsection{METHANE}

Methane has been considered as another carbon-bearing parent molecule in models of comet formation. Originally suggested by Wurm (1943) for a scenario in which comets formed in the neighborhood of the giant planets, methane has also been included at various abundance levels in early models that attempted to link comets to the interstellar clouds (Mitchell et al. 1981, Biermann et al. 1982, Yamamoto et al. 1983). A search for $\mathrm{CH}_{4}$ in Comet Halley on March 20, 1986, utilizing the Fourier Transform Spectrometer on the NASA-Kuiper Airborne Observatory, resulted in an upper limit for the gas production rate of $4 \times 10^{28}$ molecules $\mathrm{s}^{-1}$ (Drapatz et al. 1986 ), corresponding to less than $4 \%$ relative to $\mathrm{H}_{2} \mathrm{O}$. The evaluation of the $\mathrm{CH}_{4}$ abundance from the neutral gas spectra of the NMS ex- 
periment on Giotto is difficult because of possible confusion with the dissociation fragments from $\mathrm{H}_{2} \mathrm{O}$, possibly $\mathrm{NH}_{3}$, and heavier molecules that lead to interference in the mass range 12 to $16 \mathrm{amu} / \mathrm{e}$. So far, only an upper limit of $7 \%$ for the volume mixing ratio relative to water has been published by Krankowsky et al. (1986). An estimate of the $\mathrm{CH}_{4}$ abundance can be obtained from the in situ ion composition measurements. The relative abundance of ion mass peaks in the range of 12 to $19 \mathrm{amu} / \mathrm{e}$ measured by the ion mass spectrometer (IMS) experiment has been used by Allen et al. (1987) to derive a $\mathrm{CH}_{4}$ gas production rate of $2 \%$ relative to $\mathrm{H}_{2} \mathrm{O}$ by modeling the photo- and ion-chemistry in the inner coma.

Ground-based infrared spectroscopy of the $\nu_{3}$ band of $\mathrm{CH}_{4}$ around $3.3 \mu \mathrm{m}$ between March 15 and April 8, 1986, has yielded marginal estimates for the $\mathrm{CH}_{4}$ production rate (Kawara et al. 1988). Methane production rates of $0.2 \%$ to $1.2 \%$ relative to water have been derived, using assumed rotational temperatures of 50 to $200 \mathrm{~K}$. Observations of the (0-0) band of $\mathrm{CH}$ by optical spectroscopy (Wyckoff et al.1988) have shown that, in addition to $\mathrm{CH}$ from photodissociation of $\mathrm{CH}_{4}$, other parent molecules originating from the nucleus or $\mathrm{CH}$ produced in an extended source contribute to the observed $\mathrm{CH}$, which prevents the $\mathrm{CH}_{4}$ abundance from being derived. Therefore, the amount of methane in Halley is difficult to determine at present.

\subsection{AMMONIA}

Ammonia is a candidate parent molecule in comets and a possible progenitor of the observed $\mathrm{NH}$ and $\mathrm{NH}_{2}$ radicals. Together with $\mathrm{N}_{2}$, ammonia is considered to be an important source of the cosmochemically abundant element nitrogen in the volatiles of comets. The distribution of nitrogen between ammonia and molecular nitrogen is indicative of the environment where comets formed (see, e.g., Prinn and Fegley 1989). Ammonia was marginally detected by direct observation at radio wavelengths in Comet IRAS-ArakiAlcock (1983 VII) (Altenhoff et al. 1983). From the NMS experiment on Giotto, an upper limit of $10 \%$ for the volume mixing relative to $\mathrm{H}_{2} \mathrm{O}$ has been reported (Krankowsky et al. 1986). Similar to the case for $\mathrm{CH}_{4}$, improved estimates are obtained through modeling using the mass spectral data of the ion mass spectrometer on Giotto. Limits, determined from the IMS data inside the contact surface, on the $\mathrm{NH}_{3}$ production rate relative to $\mathrm{H}_{2} \mathrm{O}$ are $1 \%$ to $2 \%$ (Allen et al. 1987 ).

This derivation of the $\mathrm{NH}_{3}$ abundance has been criticized by Marconi and Mendis (1988). Their main point is that the $\mathrm{NH}_{3}$ abundance required to fit the Giotto IMS ion composition data can be drastically reduced by increasing the value used for the UV flux (which is responsible for ionizing $\mathrm{H}_{2} \mathrm{O}$ ) by a factor of ten over what Allen et al. (1987) assumed in their model. Such an increase in UV flux will also slightly decrease the photodestruction lifetime of $\mathrm{H}_{2} \mathrm{O}$. As derived from a first interpretation of the Giotto NMS measurements (Krankowsky et al. 1986), the shorter $\mathrm{H}_{2} \mathrm{O}$ lifetime-4.4 $\times 10^{4} \mathrm{~s}$, compared with the generally accepted value of $6.6 \times 10^{4} \mathrm{~s}$ for $0.9 \mathrm{AU}$ from Huebner and Carpenter (1979)-was taken as circumstantial evidence for an elevated UV flux during the Giotto encounter. However, the lifetime of water derived from the NMS Giotto measurements has been recalculated recently (Krankowsky and Eberhardt 1990), to be $5.6 \times 10^{4} \mathrm{~s}$, by taking into account the radial variation of the measured outflow velocity (Lämmerzahl et al. 1987) and by taking into account a revision of the Giotto flyby geometry. The new value of the water photodestruction lifetime agrees within $10 \%$ with the theoretical value of $6.2 \times 10^{4} \mathrm{~s}$ at $0.9 \mathrm{AU}$ on March 13, 1986 derived from a recent study of the photodissociation of water 
(Crovisier 1989), where a dependence of the photodestruction rate on the solar UV flux as characterized by the $10.7-\mathrm{cm}$ solar index has been included.

From three independent spectrophotometric observations of $\mathrm{NH}_{2}$ in the visible, Wyckoff et al. (1989b) derived for Halley a low $\mathrm{NH}_{3}$ abundance of $0.002 \pm 0.001$ relative to water. Wyckoff et al. also reported $\mathrm{NH}_{3} / \mathrm{H}_{2} \mathrm{O}$ ratios for $\mathrm{P} /$ Borrelly $(\sim 0.002)$, for HartleyGood $(\sim 0.0002)$, and for Thiele $(\sim 0.001)$. Recently, Tegler and Wyckoff $(1989)$ recalculated the $\mathrm{NH}_{2}$ fluorescence efficiencies and revised the relative $\mathrm{NH}_{3}$ abundance in Halley to $0.005 \pm 0.002$. Fabry-Perot observations of $\mathrm{NH}_{2}$ yielded an $\mathrm{NH}_{3}$ abundance of 0.001 (Magee-Sauer et al. 1988). Using the fluorescence efficiencies of Tegler and Wyckoff, the Fabry-Perot data suggest an $\mathrm{NH}_{3}$ abundance of 0.004 relative to water (Magee-Sauer et al. 1989). However, as Magee-Sauer et al. (1989) have mentioned, taking into account $K_{\mathrm{a}}^{\prime \prime}=1$ levels, which have not been sampled by the $(0,8,0)$ band in their observation, would increase the derived $\mathrm{NH}_{3}$ abundance by a factor of two, according to Arpigny (1989). There is little doubt that $\mathrm{NH}_{3}$ is present in Comet Halley. The concentration is still rather uncertain.

\subsection{MOLECULAR NITROGEN}

The significance of the abundance of $\mathrm{N}_{2}$ in relation to the abundance of $\mathrm{NH}_{3}$ in comets has been mentioned in the preceding section. Non-equilibrium models of the solar nebula (Lewis and Prinn 1980) and chemical models of dense interstellar clouds (Prasad and Huntress 1980) suggest $\mathrm{N}_{2}$ as the major chemical form of nitrogen, whereas $\mathrm{NH}_{3}$ is favored in solar nebula equilibrium models (Lewis 1972). Molecular nitrogen has not been detected in cometary spectra before $\mathrm{P} / \mathrm{Halley}$, although the $\mathrm{N}_{2}^{+}$ion was observed (Fowler 1910, Swings and Page 1948). In a preliminary evaluation of neutral mass spectral peaks at $28 \mathrm{amu} / \mathrm{e}$ from the Giot to NMS experiment, Eberhardt et al. (1986a, 1987a) derived an upper limit of $10 \%$ for the $\mathrm{N}_{2}$ gas production rate relative to $\mathrm{H}_{2} \mathrm{O}$. An improved upper limit for the $\mathrm{N}_{2}$ abundance comes from ion composition data. From the ion spectrum obtained by the Giotto IMS experiment, in the distance interval from $1.1 \times 10^{5}$ to $1.7 \times 10^{5} \mathrm{~km}$, an abundance of less than $10 \%$ for $\mathrm{N}_{2}^{+}$relative to $\mathrm{CO}^{+}$ions was deduced (Balsiger et al. 1986). With a CO abundance of $20 \%$ as measured by the ultraviolet spectrometer on the rocket flight of February 26, 1986 (Woods et al. 1986), an upper limit of $2 \%$ for the $\mathrm{N}_{2}$ has been deduced by Allen et al. (1987). Ground-based emission spectra of molecular ions in the visible provided for a still lower estimate of the $\mathrm{N}_{2}$ abundance in Comet Halley. Using the measured column density ratio $\mathrm{N}_{2}^{+} / \mathrm{CO}^{+}$and taking into account the measured $\mathrm{CO} / \mathrm{H}_{2} \mathrm{O}$ ratio, Wyckoff and Theobald (1989) deduced an $\mathrm{N}_{2}$ abundance of $4 \times 10^{-4}$ relative to water.

\subsection{FORMALDEHYDE}

When formaldehyde was detected (Snyder et al. 1969) in the interstellar gas by radio astronomy, unsuccessful searches began for $\mathrm{H}_{2} \mathrm{CO}$ in comets. At optical wavelengths, several features observed in the spectra from Comet IRAS-Araki-Alcock (1983 VII) were tentatively attributed to $\mathrm{H}_{2} \mathrm{CO}$ (Cosmovici and Ortolani 1984). In Halley, the infrared instrument IKS on VEGA 1 detected spectral features in the 3.2 to $3.7 \mu \mathrm{m}$ range which were identified as being due to formaldehyde (Combes et al. 1986, 1988). The $\mathrm{H}_{2} \mathrm{CO}$ production rate relative to $\mathrm{H}_{2} \mathrm{O}$ was estimated to be $\leq 4 \%$. Observations of the radio emission of $\mathrm{H}_{2} \mathrm{CO}$ at $6-\mathrm{cm}$ wavelength yielded a $\mathrm{H}_{2} \mathrm{CO}$ production rate of about $1.5 \%$ relative to water (Snyder et al. 1989). There is an indication in the data that $\mathrm{H}_{2} \mathrm{CO}$, in addition to its release from the nucleus, also originated from an extended source in the coma. Reanalyzing the infrared 
spectrum of the IKS experiment on VEGA 1, Mumma and Reuter (1989) retrieved an $\mathrm{H}_{2} \mathrm{CO}$ abundance of $(4.5 \pm 0.5) \%$ relative to water. This value agrees with a preliminary estimate obtained from an analysis of the radial profile of the ion with mass $30 \mathrm{amu} / \mathrm{e}$ (interpreted as $\mathrm{H}_{2} \mathrm{CO}^{+}$) from the Giotto NMS experiment, resulting in an abundance of $\sim 4.5 \%$. The derived radial density profile of $\mathrm{H}_{2} \mathrm{CO}$ seems to suggest a distributed source (Krankowsky et al. 1990). In infrared spectra obtained from the ground, Knacke et al. (1986) and Danks et al. (1987) found features that they attributed to the $\nu_{1}$ and $\nu_{5}$ bands of $\mathrm{H}_{2} \mathrm{CO}$, whereas such features were not seen in the spectra measured by Baas et al. (1986) and Wrickramasinghe and Allen (1986). Recently, formaldehyde has been observed in Comet Machholz (1988j) with a production rate a factor of ten larger than that in Halley (Snyder et al. 1990).

\subsection{HYDROGEN CYANIDE AND METHYL CYANIDE}

Spectral lines of the CN radical are among the most prominent signatures at optical wavelengths in comets. Hydrogen cyanide has been expected to be one of the possible parent molecules of CN. Its detection by radio astronomy was claimed for the first time in Comet Kohoutek (1973 XII) (Huebner et al. 1974). Then for many years searches for HCN in other comets by radio spectroscopy were not successful or gained marginal results (see Winnberg et al. 1987). Three groups (Schloerb et al. 1986, Despois et al. 1986, Winnberg et al. 1987) have detected $\mathrm{HCN}$ in Halley, with an abundance of about $0.1 \%$ that of water. In effect, $\mathrm{HCN}$ is one of the best monitored parent molecules in Halley, with the HCN production rate following closely the dust and gas activity. Comparison with the $\mathrm{CN}$ production suggests that $\mathrm{HCN}$ is an important parent for $\mathrm{CN}$, although indications hint that it is not the only parent (Schloerb et al. 1987, Despois et al. 1986). The 28-amu/e peak in the ion spectra from the Giotto IMS experiment interpreted as being mainly due to protonated hydrogen cyanide $\mathrm{H}_{2} \mathrm{CN}^{+}$has been utilized to derive $\mathrm{HCN}$ abundances by photochemical modeling (Ip et al. 1990). An upper limit of $2 \times 10^{-4}$ relative to $\mathrm{H}_{2} \mathrm{O}$ has been obtained. This value is about four times lower than the value from radio observations. Ip et al. suggested that these data could indicate a minor contribution of $\mathrm{HCN}$ to $\mathrm{CN}$ in the coma of Halley. Detection of methyl cyanide $\left(\mathrm{CH}_{3} \mathrm{CN}\right)$ was claimed in Kohoutek (1973 XII) (Ulich and Conklin 1974) but never confirmed. Searches for methyl cyanide and cyano-acetylene $\left(\mathrm{HC}_{3} \mathrm{~N}\right)$, possible parents for the $\mathrm{CN}$ radical observed in Halley, resulted in upper limits only, which are on the order of $10^{-3}$ relative to water (Bockelée-Morvan et al. 1986).

\subsection{SULFUR AND HYDROCARBONS}

The radical CS has been seen in many cometary spectra since its detection in Comet West (1976 VI) (Smith et al. 1980). Observations of CS in Comet IRAS-Araki-Alcock (1983 VII) by the IUE satellite have demonstrated that the short-lived (scale length $\approx 300 \mathrm{~km}$ ) parent of CS (scale length $\approx 100,000 \mathrm{~km}$ ) is the molecule $\mathrm{CS}_{2}$ (Jackson et al. 1986). The IUE satellite monitored the CS production rate in Halley (Feldman et al. 1987). A uniform decrease in the production rate toward larger heliocentric distances was found. At the time of the spacecraft encounters at $0.9 \mathrm{AU}$, the CS production rate was $\sim 0.1 \%$ that of water, which is essentially the production rate of the parent $\mathrm{CS}_{2}$ from the nucleus. Wallis and Krishna Swamy (1987) have claimed the detection of the sulfur dimer $\mathrm{S}_{2}$-strongly disputed by Feldman (1990) -in IUE spectra from Halley with a mixing ratio of $\sim 0.001$. Also, Kim and A'Hearn (1990) have reported a possible indentification of $S_{2}$ in Halley. Thus, after A'Hearn et al. (1983) discovered the molecule $S_{2}$ in Comet IRAS-Araki-Alcock with an 
abundance of $\sim 0.05 \%$ relative to $\mathrm{OH}$, the possible detection of $\mathrm{S}_{2}$ in Halley could indicate that $S_{2}$ is a common species in comets. $\mathrm{CS}_{2}$ hardly photodissociates into $\mathrm{S}_{2}$; therefore $\mathrm{S}_{2}$ is likely a parent molecule (A'Hearn and Feldman 1984), generally not observed in spectra owing to its short photodestruction lifetime $(\approx 350 \mathrm{~s}$ at $0.9 \mathrm{AU})$. The implications of the presence of $S_{2}$ in cometary nuclei are significant for the origin of cometary matter. As A'Hearn and Feldman have pointed out, it is unlikely that solid $S_{2}$ has formed by gas phase condensation, which produces primarily other sulfur compounds. Possibly surface reactions on grains and irradiation have played a role in the formation of $S_{2}$. Furthermore, $S_{2}$ must have been preserved at temperatures below $30 \mathrm{~K}$ according to laboratory experiments by Greenberg et al. (1986). These facts are taken as arguments that interstellar matter is preserved in cometary nuclei. A tentative identification of the sulfur compound OCS in Halley has been claimed by Combes et al. (1988) on the basis of a marginal feature at $4.85 \mu \mathrm{m}$ in the spectra from the IKS infrared spectrometer on VEGA 1. For the abundance relative to water, an upper limit of $<0.01$ has been given. A radio search at millimeter wavelengths resulted in an upper limit of $<0.06$ for the relative abundance of OCS in Halley (Bockelée-Morvan et al. 1986, 1987).

A strong and broad emission feature at 3.2 to $3.5 \mu \mathrm{m}$ detected by the IKS experiment on VEGA 1 has been attributed to the $\mathrm{C}-\mathrm{H}$ stretch in saturated and unsaturated hydrocarbons (Combes et al. 1986, 1988; Encrenaz et al. 1988). For the origin of this emission, hydrocarbons in the gas phase, polycyclic aromatic hydrocarbons (PAH), and organic mantles of small grains have been considered. If the observed emission is due to solids or PAH, then the carbon production rate has been estimated to be at the percent level or less relative to water (Combes et al. 1988). For gaseous fluorescence a similar production rate for carbon was quoted originally (Combes et al. 1986). However, in the meantime, the authors have corrected this value upward by almost a factor of 100 (Combes et al. 1988). Such a high carbon production rate is not supported by the in situ gas and ion measurements in the coma of Comet Halley. Likely the emission is predominately from solids, with only small contributions from gas fluorescence. A summary of the parent molecules definitely detected in Comet Halley is shown in Table 1.

\section{Grains as a Source of Coma Gas}

Gas jets were discovered in the visible molecular emission bands of the radicals $\mathrm{CN}$ and $C_{2}$ in narrow-band filtered images of Comet Halley by A'Hearn et al. (1986a, b). These jets, seemingly independent from those in the continuum reflected from the dust, extended to projected distances of more than $50,000 \mathrm{~km}$ and persisted for several weeks. It was estimated that as much as half the amount of CN observed in the coma by Millis and Schleicher (1986) could be produced within the jets. A'Hearn and co-workers linked the observed gas jets to submicron dust particles and argued that the radicals observed in the jets were produced by the photodissociation of the parent molecules on the grain surface or from the short-lived parents released from the grains into the gas phase. The mass loss rate of the dust required to support the observed amount of the radicals in jets was estimated to be only a small fraction of the total mass loss rate of the dust from the comet (McDonnell et al. 1987, Mazets et al. 1986). The CHON particles, which are composed primarily of C, $\mathrm{H}, \mathrm{O}$, and $\mathrm{N}$ and which were detected by the particle impact analyzer experiments (PIA and PUMA) on the Giotto and VEGA spacecraft (Kissel et al. 1986), were suggested as candidate grains. Analyzed dust particles in the micrometer to submicrometer range were 
Table 1. Abundances of Probable Parent Molecules in the Coma of Comet Halley

\begin{tabular}{|c|c|c|}
\hline Species & $\begin{array}{l}\text { Gas Production Rate } \\
\text { Relative to } \mathrm{H}_{2} \mathrm{O} \text { (by number) }\end{array}$ & Instrumental Technique \\
\hline$\overline{\mathrm{CO}}$ & $\begin{array}{c}0.07^{1} \\
0.17 \cdots 0.20^{3} \\
0.15^{3}\end{array}$ & $\begin{array}{l}\text { Giotto NMS, gas spectra } \\
\text { Rocket UV experiment } \\
\text { Giotto NMS, gas spectra }\end{array}$ \\
\hline $\mathrm{CO}_{2}$ & $\begin{array}{c}\leq 0.035 \\
0.027\end{array}$ & $\begin{array}{l}\text { Giotto NMS, gas spectra } \\
\text { Vega IKS, IR spectra } \\
{ }^{5}\end{array}$ \\
\hline $\mathrm{CH}_{4}$ & $\begin{array}{c}\leq 0.07 \\
\leq 0.04 \\
\sim 0.02^{8} \\
0.002 \cdots 0.012\end{array}$ & $\begin{array}{l}\text { Giotto NMS, gas spectra }{ }^{5} \\
\text { KAO, IR spectra } \\
\text { Giotto IMS, ion spectra }^{9} \\
\text { IR spectra, ground based } \\
\text { I0 }\end{array}$ \\
\hline $\mathrm{NH}_{3}$ & $\begin{array}{c}\leq 0.1 \\
0.01 \cdots 0.02^{8} \\
0.004 \cdots 0.008\end{array}$ & $\begin{array}{l}\text { Giotto NMS, gas spectra } \\
\text { Giotto IMS, ion spectra } \\
\text { Optical spectroscopy } \\
\mathbf{1 1 , 1 2}\end{array}$ \\
\hline $\mathrm{N}_{2}$ & $\begin{array}{c}<0.1 \\
<0.02^{8} \\
\sim 0.0004\end{array}$ & $\begin{array}{l}\text { Giotto NMS, gas spectra } \\
\text { Giotto IMS, ion spectra } \\
\mathrm{N}_{2}^{+} \text {spectrophotometry } \\
\end{array}$ \\
\hline $\mathrm{H}_{2} \mathrm{CO}$ & $\begin{array}{c}0.045 \\
0.015^{3}\end{array}$ & $\begin{array}{l}\text { Vega IKS, IR spectra }{ }^{14} \\
\text { VLA, radio wave } \\
\text { 15 }\end{array}$ \\
\hline $\mathrm{HCN}$ & $\begin{aligned} & \sim 0.001 \\
& \sim 0.0002^{8}\end{aligned}$ & $\begin{array}{l}\text { Millimeter spectra }^{16,17,18} \\
\text { Giotto IMS, ion spectra } \\
\end{array}$ \\
\hline \multicolumn{2}{|c|}{$\begin{array}{l}{ }^{1} \text { Released from nucleus. } \\
{ }^{2} \text { Eberhardt et al. }(1986 \mathrm{~b}, 1987 \mathrm{~b}) \text {. } \\
{ }^{3} \text { Released from nucleus and extended source. } \\
{ }^{4} \text { Woods et al. }(1986) . \\
{ }^{5} \text { Krankowsky } \text { et } \text { al. }(1986) . \\
{ }^{6} \text { Combes } \text { et al. }(1988) . \\
{ }^{7} \text { Drapatz et al. }(1986) \text {. } \\
{ }^{8} \text { Inferred from models of coma. } \\
{ }^{9} \text { Allen et al. }(1987) . \\
{ }^{10} \text { Kawara et al. }(1988) .\end{array}$} & $\begin{array}{l}{ }^{11} \text { Tegler and Wyckoff }(1989) . \\
{ }^{12} \text { Magee-Sauer et al. }(1989) . \\
{ }^{13} \text { Wyckoff and Theobald (1989). } \\
{ }^{14} \text { Mumma and Reuter (1989). } \\
{ }^{15} \text { Snyder } \text { et al. }(1989) . \\
{ }^{16} \text { Despois et al. }(1986) . \\
{ }^{17} \text { Schloerb et al. }(1986) . \\
{ }^{18} \text { Winnberg } \text { et al. }(1987) . \\
{ }^{19} \text { Ip et al. (1990). }\end{array}$ \\
\hline
\end{tabular}

found to be composed essentially of two components, a silicate-like and a refractory organic fraction, in proportions varying from particle to particle (Kissel et al. 1986, Clark et al. 1986, Jessberger and Kissel 1990). A quantitative study of photosputtering from CHON grains and of the spatial development of trace gas jets as possible mechanisms for the gas jet formation seemed to suggest the feasibility of both processes to produce gas jets (Combi 1987).

The idea of grains releasing gas into the coma has been strengthened by the discovery of an extended source of $\mathrm{CO}$ in the coma (Eberhardt et al. 1986a, 1987a). At a distance of $1,000 \mathrm{~km}$, a $\mathrm{CO}$ gas production rate of $7 \%$ relative to $\mathrm{H}_{2} \mathrm{O}$ was found, increasing to $15 \%$ at $20,000 \mathrm{~km}$. The radial distribution of the extended CO source was calculated, and the maximum of $\mathrm{CO}$ gas production was found at $\sim 9,000 \mathrm{~km}$. Micron-sized dust particles 
of the CHON type were proposed as a source for the additional $\mathrm{CO}$. It has been noted that Vaisberg et al. (1986) observed a distinct variation of the grain size distribution with distance from the nucleus. Small grains become overabundant, and the relative abundance of the medium-sized grains seems to decrease with increasing distance. The depletion starts near the nucleus $(R \leq 10,000 \mathrm{~km})$, with grains in the $10^{-14}$ to $10^{-13} \mathrm{~g}$ range. This has been interpreted as the result of fragmentation of larger grains. Aggregate particles seem to lose their interstitial material and eventually break up into very small grains (Eberhardt $e t$ al. $1986 \mathrm{a}, 1987 \mathrm{a}$ ). This process proceeds faster with smaller grains, and the lifetime of the aggregates should increase with their size. Once the breakup begins, additional surfaces of volatile material will be exposed, leading to an enhancement of the gas production. The shape of the source function and the location of the maximum at $\sim 9,000 \mathrm{~km}$ is in qualitative agreement with the results of Vaisberg et al. (1986).

Further support for such a mechanism comes from the analysis of the measured distribution of $\mathrm{H}_{2} \mathrm{CO}$ in the coma (Snyder et al. 1989, Krankowsky et al. 1990). Both independent data sets seem to require the existence of an extended source of $\mathrm{H}_{2} \mathrm{CO}$ in Halley's coma. The chemical nature of the material in the grains releasing $\mathrm{CO}, \mathrm{CN}$, and $\mathrm{H}_{2} \mathrm{CO}$ or the short-lived parent of these species is, at present, uncertain. The proposed photolyzed outer mantle of interstellar grains (Greenberg 1982) could be the source of evaporating organic molecules, including $\mathrm{CO}$ or a parent of it. In interstellar clouds, $\mathrm{CO}$ is condensing directly on the grain surfaces as solid CO (Lacy et al. 1984), which requires temperatures as low as $17 \mathrm{~K}$ (Léger 1983). Laboratory irradiation with $\mathrm{UV}$ of $\mathrm{CO}, \mathrm{NH}_{3}$, and other ice mixtures has shown that molecules containing cyano $(\mathrm{C} \equiv \mathrm{N})$ groups are formed, and that these reaction products have much lower vapor pressure and are not lost even at temperatures as high as $150 \mathrm{~K}$ (Lacy et al. 1984). From IR absorption spectra, Lacy et al. conclude that formation of molecules, containing the cyano group, also occurs on the interstellar grains. The observation of the extended $\mathrm{CO}$ and $\mathrm{CN}$ sources in the coma of Comet Halley may thus be an indication for the presence of relatively unaltered interstellar grains in the nucleus.

Interpreting spectra obtained by the positive ion cluster analyzer (PICCA) experiment on the Giotto spacecraft, Huebner (1987) and Mitchell et al. (1987) proposed the existence of polymerized formaldehyde $\left(\left(\mathrm{H}_{2} \mathrm{CO}\right)_{n}\right)$, also known as polyoxymethylene (POM), in dust grains of Halley. They argued that impact or photodissociation will disintegrate POM into compounds that consist of alternating methylene $\left(\mathrm{CH}_{2}\right)$ and atomic oxygen units, which were presumably detected as ions by the PICCA instrument (Korth et al. 1986, Mitchell et al. 1986). Decomposition of POM was proposed as the mechanism for the extended source of $\mathrm{CO}$ and as the source for $\mathrm{H}_{2} \mathrm{CO}$. The affinity of POM to silicates and graphite suggests POM as the interstitial glue of the CHON dust particles, bonding submicron grains into larger particles which disintegrate when the glue has evaporated. As discussed above, this process could then explain the observed change in the dust particle size distribution around $10,000 \mathrm{~km}$ from the nucleus (Vaisberg et al. 1986). Other polymers containing atomic nitrogen or cyanide radicals could represent the source for the observed $\mathrm{CN}$ jets.

The mass ratio of POM to dust was estimated to be $\sim 0.02$ at $10,000 \mathrm{~km}$, assuming a dust-to-gas mass ratio of 0.3 (Mitchell et al. 1987). The revised dust-to-gas mass ratio of $\sim 1$ of McDonnell et al. (1987) - with an extrapolation of the size distribution to onekilogram particles-lowers the POM to dust mass ratio to $\sim 0.006$. However, in order to account for the $\mathrm{CO}$ released from grains, a $\mathrm{CO}$ production rate relative to $\mathrm{H}_{2} \mathrm{O}$ of $\sim 8 \%$ is required (Eberhardt et al. 1987a). This number translates into a mass ratio of CO to dust of $\sim 0.1$ (dust/gas $\approx 1$ assumed). The POM/dust ratio would have to be higher than 0.1 , 
as only a fraction of the POM dissociates into $\mathrm{CO}$. This is not only in disagreement with the estimate of the mass ratio of POM to dust, but also means that a very substantial fraction of the grains would have to evaporate, although the evaporated grains are not necessarily included in the dust production rate, as this rate is based partly on dust densities measured at distances $>8,000 \mathrm{~km}$.

Therefore, despite the fact that POM offers an attractive qualitative explanation, a severe mass balance problem seems to exist. This argument is fairly insensitive to the assumed dust/gas mass ratio, which can only increase noticeably when the number of large dust particles in the size distribution, not measured by the dust detectors on VEGA and Giotto, is increased. However, such particles contribute little to the presumed gas release. A solution to the mass balance problem could lie at the opposite end of the dust size distribution. If very many particles with masses $\ll 10^{-17} \mathrm{~g}$ have been present in the coma, they would have escaped detection by the dust detectors. Indications for the existence of very many particles in the mass range of $10^{-17}$ to $10^{-20} \mathrm{~g}$ are in the quasi-noise events found in non-triggered spectra of the PUMA particle impact analyzer on the VEGA spacecraft (Sagdeev et al. 1989, Kissel 1989, private communication).

A puzzling recent discovery (Kim et al. 1989) is that the spectral features of $\mathrm{NH}$ in the (0-0) band observed in Halley almost totally fluoresce with negligible contributions from collisions. This indicates that $\mathrm{NH}$ exists mainly at distances from the nucleus larger than $30,000 \mathrm{~km}$. The authors conclude that $\mathrm{NH}$ cannot be a direct dissociation product from $\mathrm{NH}_{3}$. Other, more complex molecules and dust grains are proposed as possible sources.

Irrespective of the chemical nature of the $\mathrm{CN}-, \mathrm{CO}-, \mathrm{H}_{2} \mathrm{CO}-$, and perhaps $\mathrm{NH}$ containing compounds in the dust grains, the problem remains of understanding how such a large amount of $\mathrm{CO}$ is released in a relatively short time after the dust left the nucleus. Therefore, as an alternative, anisotropic outgassing from the nucleus should be considered. Images from the VEGA and Giotto missions have shown that the emission of dust and (presumably) gas from the nuclear surface was highly anisotropic. Although it can be expected that an anisotropic localized outgassing will become isotropicized at larger distances, due to the lateral pressure gradients close to the nucleus, as well as due to the increasing gas temperature from chemical heating further out, numerical calculations by Kitamura (1986) and Kömle and Ip (1986) have shown recognizable anisotropies in the outflow to still persist at a distance of a few thousand kilometers.

However, no noticable structures seem to be present in the radial profile of $\mathrm{H}_{2} \mathrm{O}$ along the Giotto trajectory which would be expected from bulk anisotropies. Another, perhaps more likely alternative is a locally enhanced $\mathrm{CO} / \mathrm{H}_{2} \mathrm{O}$ ratio in one or several of the active regions on the nucleus. Combi (1987) has proposed that such trace gas jets remain fairly well focused even at large cometocentric distances. Combi's alternative mechanism of a collimated flow of CHON grains being photosputtered is critically dependent on the grain sizes. Submicron-sized particles are quickly lost from the jet due to the solar radiation pressure. The localized injection of a trace gas, in Combi's model, does not disturb the expansion of the bulk and other trace gases. Also, temporal variations in the $\mathrm{CO} / \mathrm{H}_{2} \mathrm{O}$ ratio at the nucleus would result in radial changes of the coma gas composition without necessarily influencing the bulk gas properties. It is obvious that such variability in the composition of the volatiles has implications for the formation of Comet Halley as well as for its evolution during earlier passages through the inner solar system. 


\section{Isotopic Composition}

Isotopic abundances from measurements in the volatile fraction of Comet Halley have been reported so far (Table 2) for the elements hydrogen, carbon, nitrogen, oxygen, and sulfur. The ${ }^{34} \mathrm{~S} /{ }^{32} \mathrm{~S}$ ratio as determined from ion mass spectra in the inner coma was $0.045 \pm 0.010$ (Krankowsky et al. 1986), in agreement with the terrestrial ratio of 0.044 . The mass spectrometric measurement of the isotopic composition of light volatile elements in the coma is difficult, because the low-abundance isotopes are always heavier than the abundant isotopes and can thus be masked by hydrides. Only for the ion $\mathrm{H}_{3} \mathrm{O}^{+}$is the interference with other masses, expected on the isotopic $\mathrm{H}_{2} \mathrm{DO}^{+}$, limited to a few possible species, which can be corrected for with sufficient accuracy. From such spectra, Eberhardt et al. (1987b) deduced a value of $0.0023 \pm 0.0006$ for the ${ }^{18} \mathrm{O} /{ }^{16} \mathrm{O}$ ratio in the water of Halley. While this figure is identical with the terrestrial ratio, the errors in the preliminary evaluation are too large for a meaningful comparison with observed meteoritic ${ }^{16} \mathrm{O}$ abundance variations. For the hydrogen in Halley's water, Eberhardt et al. (1986b, 1987b) found an isotopic ratio of $0.6 \times 10^{-4} \leq \mathrm{D} / \mathrm{H} \leq 4.8 \times 10^{-4}$. The wide limits for the $\mathrm{D} / \mathrm{H}$ isotope ratio come from the still uncertain abundance of $\mathrm{NH}_{3}$ in Halley. The contribution of $\mathrm{H}_{2}{ }^{18} \mathrm{O}^{+}$to the measured signal on mass $20 \mathrm{amu} / \mathrm{e}$ depends on the relative abundance of the ions $\mathrm{H}_{2} \mathrm{O}^{+}$ and $\mathrm{NH}_{4}^{+}$in the coma. In comparison, Schleicher et al. (1986) obtained an upper limit of $\mathrm{OD} / \mathrm{OH} \leq 4 \times 10^{-4}$ for the Comet Halley from IUE observations. Emission lines of ${ }^{13} \mathrm{C}^{14} \mathrm{~N}$ resolved for the first time in ground-based spectra have been utilized to determine the ${ }^{12} \mathrm{C} /{ }^{13} \mathrm{C}$ isotope ratio of $\mathrm{CN}$ in Comet Halley (Wyckoff et al. $1989 \mathrm{a}$ ). $\mathrm{A}^{12} \mathrm{C} /{ }^{13} \mathrm{C}$ ratio of $65 \pm 9$ has been found, which is $2.7 \sigma$ lower than the bulk solar system value (89.9). For the nitrogen isotope ratio ${ }^{14} \mathrm{~N} /{ }^{15} \mathrm{~N}$, a $2 \sigma$ lower bound of 200 has been estimated, consistent with the bulk solar system ratio of 250 . As discussed by Wyckoff et al., carbon isotope measurements in four comets have been obtained previously. In all cases, $\mathrm{C}_{2}(1,0) \mathrm{Swan}$ band intensities of the isotopes were used. Within the large error bars, the isotope ratios retrieved are compatible with the solar system value.

Despite the relatively wide limits on the deuterium abundance found in Halley's water, some conclusions with respect to the origin of the cometary water are evident (Eberhardt et al. $1986 \mathrm{~b}, 1987 \mathrm{~b})$. The deuterium abundance in Halley is comparable to the $\mathrm{D} / \mathrm{H}$ ratio in the solar sytem objects poor in hydrogen, such as the Earth, the silicate fraction in meteorites, and Titan. But Halley's water is distinctly enriched in deuterium compared with the protosolar hydrogen and with hydrogen accreted in gaseous form from the solar nebula in bodies such as Jupiter and Saturn. In contrast, some molecules in interstellar molecular clouds (IMC) show a much larger enrichment due to deuteration by ion-molecule reactions. As noted by Geiss $(1987,1988)$, this does not preclude IMCs from having contributed to cometary water, because condensation could have interrupted deuteration of water.

Wyckoff et al. (1989a) have argued that the approximately $35 \%$ enrichment in ${ }^{13} \mathrm{C}$ observed in $\mathrm{CN}$ relative to the bulk solar system value is not compatible with the formation of cometary nuclei in the vicinity of Uranus and Neptune. Measurements of the ${ }^{12} \mathrm{C} /{ }^{13} \mathrm{C}$ ratio in the outer solar system currently agree with the solar value (de Bergh 1988). However, $\mathrm{CN}$ in Halley is only a minor species, comprising less than $1 \%$ of the volatile carbon inventory of the comet (cf. Table 1). Meteorites were most probably formed within the orbit of Jupiter. Nevertheless, they contain minor phases showing isotopic anomalies including ${ }^{13} \mathrm{C}$ enrichment due to incomplete mixing within the solar system of components from different nucleosynthesis sites. The highest observed ${ }^{13} \mathrm{C}$ enrichment of about $3,000 \%$ 
Table 2. Isotope Ratios Measured in the Volatile Fraction in the Coma of Comet Halley

\begin{tabular}{|c|c|l|}
\hline Element & Isotope Ratio & Chemical Form Measured \\
\hline $\mathrm{D} / \mathrm{H}$ & $0.6 \times 10^{-4}-4.8 \times 10^{-4}$ & Water, protonated ions ${ }^{1}$ \\
${ }^{12} \mathrm{C} /{ }^{13} \mathrm{C}$ & $65 \pm 9$ & Cyanide radical $^{2}$ \\
${ }^{14} \mathrm{~N} /{ }^{15} \mathrm{~N}$ & $\geq 200$ & Cyanide radical $^{2}$ \\
${ }^{18} \mathrm{O} /{ }^{16} \mathrm{O}$ & $0.0023 \pm 0.0006$ & Water, protonated ions $^{1}$ \\
${ }^{34} \mathrm{~S} /{ }^{32} \mathrm{~S}$ & $0.045 \pm 0.010$ & Sulfur ion $^{3}$ \\
\hline${ }^{1}$ Eberhardt et al. $(1987 \mathrm{~b})$. & \\
${ }^{2}$ Wyckoff et al. $(1989)$. & \\
${ }^{3}$ Krankowsky et al. $(1986)$.
\end{tabular}

corresponds to ${ }^{12} \mathrm{C} /{ }^{13} \mathrm{C}=3.0$ (Wopenka et al. 1989). There is strong evidence that a sizeable fraction ( $50 \%$ to $90 \%$ ) of the cometary CN stems from CHON particles (A'Hearn et al. 1986a,b; A'Hearn 1988). If only $2 \%$ by number of the CN originated from CHON particles with ${ }^{12} \mathrm{C} /{ }^{13} \mathrm{C} \approx 4$, corresponding to the equilibrium value for $\mathrm{CNO}$ burning in stars (Iben 1975), then the ${ }^{12} \mathrm{C} /{ }^{13} \mathrm{C}$ ratio of $\mathrm{CN}$ is lowered from 89.9 to $66^{3}$. Some information on the carbon isotope ratio in grains was gained from the particle impact analyzer (PUMA) on VEGA 1. The ${ }^{12} \mathrm{C} /{ }^{13} \mathrm{C}$ ratios observed range from 1 to 5,000 (Jessberger and Kissel 1990). But as was noted, the values smaller than 89.9 suffer from interference with the hydride ${ }^{12} \mathrm{CH}$, which is not resolved from ${ }^{13} \mathrm{C}$ in the mass spectrometer. No simple instrumental explanation for the values greater than 89.9 exists. A carbon isotope ratio as high as ${ }^{12} \mathrm{C} /{ }^{13} \mathrm{C}=159$ was discovered in a silicon carbide aggregrate from the Murchison carbonaceous chondrite (Ming et al. 1989, Zinner et al. 1989). The authors infer much higher ratios in single grains that so far have not been analyzed. In graphite grains from the Murchison meteorite, anomalous carbon with ${ }^{12} \mathrm{C} /{ }^{13} \mathrm{C} \sim 4500$ has been found (Zinner and Wopenka 1990). Special nucleosynthesis sites and/or ion-molecule reactions were proposed to explain ${ }^{12} \mathrm{C} /{ }^{13} \mathrm{C}$ ratios higher than 89.9. As the isotopic composition of the bulk carbon in Halley (volatile and solid phase) is at present unknown, any conclusions based on the available carbon isotopic composition seem premature.

\section{Elemental Abundance and Origin of Comets}

In inferring the bulk chemical composition of Halley from the measurements performed in the coma, limitations must be kept in mind. What has been observed is the material from an outer layer that probably has been modified from its original state by previous passes through the inner solar system. This is particularly true for the volatiles. Prialnik and Bar-Nun (1987) have studied the thermal evolution of an initially very cold object in a Halley-like orbit. The phase transition from amorphous to crystalline ice is a major internal heat source. The transition occurs episodically, and the energy release during the amorphous to cubic transition at $137 \mathrm{~K}$ is sufficient to raise the temperature above the

\footnotetext{
${ }^{3}$ Based on an erroneous calculation Wyckoff et al. (1989) discussed and discarded the possibility that ${ }^{13} \mathrm{C}$-rich $\mathrm{CHON}$ particles could substantially lower the ${ }^{12} \mathrm{C} /{ }^{13} \mathrm{C}$ ratio in $\mathrm{CN}$. The assumptions of Wyckoff et al. (that $10 \%$ of the CHON particles have ${ }^{12} \mathrm{C} /{ }^{13} \mathrm{C} \approx 4$ and $50 \%$ of the CN stems from CHON particles) would give ${ }^{12} \mathrm{C} /{ }^{13} \mathrm{C}=48$, considerably lower than the measured value of 65 .
} 
cubic to hexagonal transition temperature of $160 \mathrm{~K}$. Each transformation episode converts a layer several tens to several hundreds of meters thick. A large fraction of gases such as $\mathrm{CO}, \mathrm{CH}_{4}$, and $\mathrm{N}_{2}$ trapped at very low temperatures are released during the warming and phase transition. Prialnik and Bar-Nun (1987) argue that a fraction of the released gas may be trapped in gas pockets. In later apparitions, such gas pockets may be vented explosively. Thus, deeper layers of still amorphous, gas-rich ice can be exposed. The implications of this model for the present discussion are twofold. If most of the $\mathrm{H}_{2} \mathrm{O}$ in the coma stems from the transformed surface shell of hexagonal ice, then the observed volatiles $\mathrm{CO}, \mathrm{N}_{2}, \mathrm{CH}_{4}$ etc. are probably highly depleted compared with their initial abundance in the pristine ice. The depletion factors can be different for the different molecules. Conclusions about the origin of the cometary volatiles based on the observed abundance of $\mathrm{CO}, \mathrm{N}_{2}, \mathrm{CH}_{4}, \mathrm{NH}_{3}$, etc. in the coma must thus be viewed with caution.

The mass spectra from the NMS experiment on Giotto have shown that $80 \%$ of the volatiles making up the ice are water. The remaining $20 \%$ are accounted for by the parent molecules listed in Table 1 , if the uncertainties in their relative abundances are taken into account. The molecular composition of the dust is more uncertain, however. The particle impact analyzers essentially determined the elemental composition, although from the relative abundances of key elements, by comparison with meteorites and interplanetary dust particles (IDP), extrapolations towards the mineralogical and structural aspects of the dust in Halley have been made (for a review, see Jessberger and Kissel 1990). The existence of a silicate-like and a refractory organic fraction has been discovered. The infrared observations attested to the presence of hydrocarbons in the dust, but left open the molecular forms and the abundances. That dust is also a carrier of volatile species has evolved from the detection of the $\mathrm{CN}$ and $\mathrm{C}_{2}$ jets and from the detection of extended sources of $\mathrm{CO}$ and possibly $\mathrm{H}_{2} \mathrm{CO}$.

Various attempts-sometimes very detailed and speculative - to deduce the elemental inventory of comets (dust and gas) have been made recently (Geiss 1987, 1988; Delsemme 1988; Encrenaz et al. 1988; Jessberger and Kissel 1990). A factor of uncertainty common to these elemental balance sheets is the dust/gas mass ratio. The abundances of rockforming elements as measured in the dust are within a factor of two relative to the solar system abundances (Jessberger and Kissel 1990). Hydrogen is strongly depleted relative to the solar system. The puzzle of the missing carbon in comets seems to be solved. The refractory organics probably account for the deficit. While oxygen is represented in nearly solar proportion in the inventory, the authors, with the exception of Delsemme, agree on a nitrogen depletion in Halley.

A clue to the origin of comets lies in the distribution of carbon and nitrogen among their volatile molecular forms $\mathrm{CO}$ and $\mathrm{CH}_{4}$, and $\mathrm{N}_{2}$ and $\mathrm{NH}_{3}$. In interstellar clouds, ionmolecule reactions at low temperatures favor the formation of $\mathrm{CO}$ and $\mathrm{N}_{2}$ (Prasad and Huntress 1980, Mitchell et al. 1981). Condensation in a gas of solar composition at low pressure (10-4 atm) under equilibrium conditions (e.g., Lewis 1972; Anders 1986) does not resemble the abundances of the volatiles and the molecular forms of carbon and nitrogen in the coma of Halley, as noted by Geiss (1988). Homogeneous gas-phase chemistry in the solar nebula under equilibrium conditions and low pressure (e.g., Prinn and Fegley 1989) leads to a conversion of $\mathrm{CO}$ into $\mathrm{CH}_{4}$ (and $\mathrm{CO}_{2}$ ) and of $\mathrm{N}_{2}$ into $\mathrm{NH}_{3}$. But kinetic effects (Lewis and Prinn 1980) inhibit the conversion as the solar nebula cools and the molecular reaction time constants become comparable to the mixing times in the nebula, leaving $\mathrm{CO}$ and $\mathrm{N}_{2}$ as the dominant molecular forms of carbon and nitrogen $\left(\mathrm{CO} / \mathrm{CH}_{4} \gg 1\right.$ and $\left.\mathrm{N}_{2} / \mathrm{NH}_{3} \gg 1\right)$. In 
the postulated higher pressure environments in subnebulae around the giant protoplanets, however, kinetic quenching of the $\mathrm{CO} \Rightarrow \mathrm{CH}_{4}, \mathrm{~N}_{2} \Rightarrow \mathrm{NH}_{3}$, and $\mathrm{CO} \Rightarrow \mathrm{CO}_{2}$ conversions is shifted to lower temperatures (Fegley and Prinn 1989) favoring the reduced forms of carbon and nitrogen $\left(\mathrm{CO} / \mathrm{CH}_{4} \ll 1\right.$ and $\left.\mathrm{N}_{2} / \mathrm{NH}_{3} \ll 1\right)$. In Halley, $\mathrm{CO} / \mathrm{CH}_{4}$ and $\mathrm{N}_{2} / \mathrm{NH}_{3}$ are intermediate between the molecular ratios expected for the interstellar material and the solar nebula, which points to some processing of Halley's volatiles in the subnebulae of the giant protoplanets, according to Fegley and Prinn (1989). The apparent nitrogen deficit in Halley, compared with the solar abundance, suggests that a sizeable fraction did not condense or was lost later. The reason could be that nitrogen was mainly present in the form of $\mathrm{N}_{2}$ when Halley formed. In contrast, as Geiss (1988) noted, the similarly volatile $\mathrm{CO}$ bonds weakly to metals and other substances, which could have been responsible for its better retention. In addition, to a large part $\mathrm{CO}$ resides in Halley's dust in the form of $\mathrm{H}_{2} \mathrm{CO}$, POM, or other refractory organics, as implied by the observation of the distributed CO source (Eberhardt et al. 1987a).

The isotopic data observed in Halley (section 4) neither rule out nor confirm an interstellar origin of Halley's water. The ${ }^{13} \mathrm{C}$ enrichment discovered in $\mathrm{CN}$ indicates the presence of unaltered interstellar material likely preserved in the dust grains. If the isotope ratios ${ }^{12} \mathrm{C} /{ }^{13} \mathrm{C} \gg 89.9$ found in a few dust particles (Jessberger and Kissel 1990) are real, then carbon from different nucleosynthesis sites has been incorporated into Halley.

ACKNOWLEDGMENT. This work has been supported by the Bundesminister für Forschung und Technologie through Grant 010F85120.

\section{References}

A'Hearn, M. F. (1988). Private communication; quoted in Wyckoff et al. (1989).

A'Hearn, M. F., Dwek, E., and Tokunaga, A. T. (1984). Infrared photometry of comet Bowell and other comets. Astrophys. J. 282, 803-806.

A'Hearn, M. F., and Feldman, P. D. (1984). $\mathrm{S}_{2}$ : A clue to the origin of cometary ice? In Ices in the Solar System, eds. J. Klinger, D. Benest, A. Dollfus, and R. Smoluchowski (Dordrecht: Reidel), 463-471.

A'Hearn, M. F., Feldman, P. D., and Schleicher, D. G. (1983). The discovery of $S_{2}$ in the coma of comet IRAS-Araki-Alcock 1983d. Astrophys. J. 274, L99-L103.

A'Hearn, M. F., Hoban, S., Birch, P. V., Bowers, C., Martin, R., and Klinglesmith, D. A. (1986a). Cyanogen jets in comet Halley. Nature 324, 649-651.

A'Hearn, M. F., Hoban, S., Birch, P. V., Bowers, C., Martin, R., and Klinglesmith, D. A. (1986b). Gaseous jets in comet P/Halley. Proc. 20th ESLAB Symposium on the Exploration of Halley's Comet, ESA SP-250, Vol. I, 483-486.

Allen, M., Delitsky, M., Huntress, W., Yung, Y., Ip, W.-H., Schwenn, R., Rosenbauer, H., Shelley, E., Balsiger, H., and Geiss, J. (1987). Evidence for methane and ammonia in the coma of Comet Halley. Astron. Astrophys. 187, 505-512.

Altenhoff, W. J., Batrla, W., Huchtmeier, W. K., Schmidt, J., Stumpf, P., and Walmsley, M. (1983). Radio observations of Comet 1983d. Astron. Astrophys. 125, L19-L22.

Anders, E. (1986). What can meteorites tell us about comets? ESA-SP 249, 31-39.

Arpigny, C. (1989). Private communication; quoted in Magee-Sauer et al. (1989). 
Arpigny, C., Dossin, F., Woszczyk, A., Donn, B., Rahe, J., and Wyckoff, S. (1990). Atlas of cometary spectra. (Dordrecht: Kluwer Academic Publishers), in press.

Baas, F., Geballe, T. R., and Walther, D. M. (1986). Spectroscopy of the 3.4 micron emission feature in Comet Halley. Astrophys. J. Lett. 311, L97-L101.

Balsiger, H., Altwegg, K., Bühler, F., Geiss, J., Ghielmetti, A. G., Goldstein, B. E., Huntress, W. T., Ip, W.-H., Lazarus, A. J., Meier, A., Neugebauer, M., Rettemund, U., Rosenbauer, H., Schwenn, R., Sharp, R. D., Shelley, E. G., Ungstrup, E., and Young, D. T. (1986). Ion composition and dynamics at comet Halley. Nature 321, 330-334.

Biermann, L., Giguere, P. T., and Huebner, W. F. (1982). A model of a comet coma with interstellar molecules in the nucleus. Astron. Astrophys. 108, 221-226.

Bockelée-Morvan, D., Crovisier, J., Despois, D., Forveille, T., Gérard, E., Schraml, J., and Thum, C. (1986). A search for parent molecules at millimeter wavelengths in comets Giacobini-Zinner 1984e and P/Halley 1982i. Proc. 20th ESLAB Symposium on the Exploration of Halley's Comet, ESA SP-250, Vol. I, 365-367.

Bockelée-Morvan, D., Crovisier, J., Despois, D., Forveille, T., Gérard, E., Schraml, J., and Thum, C. (1987). Molecular observations of Comets P/Giacobini-Zinner 1984e and P/Halley 1982i at millimeter wavelengths. Astron. Astrophys. 180, 253-262.

Boyarchuk, A. A., Grinin, V. P., Sheikhet, A. I., and Zvereva, A. M. (1987). Pre- and postperihelion Astron ultraviolet spectrophotometry of Comet Halley: A comparative analysis. Sov. Astron. Lett. 13, 92-96.

Campins, H., Rieke, G. H., and Lebofsky, M. J. (1983). Ice in Comet Bowell. Nature 301, 405.

Clark, B., Mason, L. W., and Kissel, J. (1986). Systematics of the "CHON" and other light-element particle populations in Comet Halley. Proc. 20th ESLAB Symposium on the Exploration of Halley's Comet, ESA SP-250, Vol. III, 353-358.

Combes, M., Moroz, V., Crifo, J. P., Bibring, J. P., Coron, N., Crovisier, J., Encrenaz, T., Sanko, N., Grigoriev, A., Bockelée-Morvan, D., Gispert, R., Emerich, C., Lamarre, J. M., Rocard, F., Krasnopolsky, V., and Owen, T. (1986). Detection of parent molecules in Comet Halley from the IKS-experiment. Proc. 20th ESLAB Symposium on the Exploration of Halley's Comet, ESA SP-250, Vol. I, 353-358.

Combes, M., Moroz, V. I., Crovisier, J., Encranez, T., Bibring, J. P., Grigoriev, A. V., Sanho, N. F., Coron, N., Crifo, J. F., Gispert, R., Bockelée-Morvan, D., Nikolsky, Yu. V., Krasnopolsky, V. A., Owen, T., Emerich, C., Lamarre, J. M., and Rocard, F. (1988). The 2.5-12 $\mu \mathrm{m}$ spectrum of Comet Halley from the IKS-VEGA experiment. Icarus 76, 404-436.

Combi, M. R. (1987). Sources of cometary radicals and their jets: Gases or grains. Icarus 71, 178-191.

Combi, J. R., and Delsemme, A. H. (1980). Neutral cometary atmospheres 1. An average random walk model of photodissociation in comets. Astrophys. J. 237, 633-640.

Cosmovici, C. B., and Ortolani, S. (1984). Formaldehyde in Comet IRAS-Araki-Alcock (1983d). Cosmogonical implications. In Ices in the Solar System, eds. J. Klinger, D. Benest, A. Dollfus, and R. Smoluchowski (Dordrecht: Reidel), 473-485.

Craven, J. D., and Frank, L. A. (1987). Atomic hydrogen production rates for Comet $\mathrm{P} /$ Halley from observations with Dynamics Explorer 1. Astron. Astrophys. 187, 351-356. 
Crifo, J. F. (1983). Visible and infrared emissions from volatile and refractory cometary dust. A new interpretation of Comet Kohoutek observations. In Cometary Exploration, ed. T. I. Gombosi, Hungarian Acad. Sci II, 167-176.

Crifo, J. F. (1989). Water clusters in the coma of Comet Halley and their effect on gas density, temperature, and velocity. Icarus, in press.

Crovisier, J. (1989). The photodissociation of water in cometary atmospheres. Astron. Astrophys. 213, 459-464.

Crovisier, J., Despois, D., Gerard, E., Irvine, W. M., Kazes, I., Robinson, S., and Schloerb, F. P. (1981). A search for the 1.35-cm line of $\mathrm{H}_{2} \mathrm{O}$ in comets Kohler (1977 XIV) and Meier (1978 XXI). Astron. Astrophys. 97, 195-198.

Crovisier, J., and Schloerb, F. P. (1990). The study of comets at radio wavelengths. (this book)

de Bergh, C. (1988). Private communication; quoted in Wyckoff et al. (1989a).

Danks, A. C., Encranez, T., Bouchet, P., Le Bertre, P., and Chalabaev, A. (1987). The spectrum of Comet P/Halley from 3.0 to $4.0 \mu \mathrm{m}$. Astron. Astrophys. 184, 329-332.

Delsemme, A. H. (1988). The chemistry of comets. Phil. Trans. R. Soc. Lond. A 325, 509-523.

Delsemme, A. H., and Swings, P. (1952). Hydrates de gaz dans les noyaux comètaires et les grains interstellaires. Ann. d'Astrophys. 15, 1-6.

Despois, D., Crovisier, J., Bockelée-Morvan, D., Schraml, J., Forveille, T., and Gérard, E. (1986). Observations of hydrogen cyanide in Comet Halley. Astron. Astrophys. 160, 11-12.

Drapatz, S., Larson, H. P., and Davis, D. S. (1986). Search for methane in Comet Halley. Proc. 20th ESLAB Symposium on the Exploration of Halley's Comet, ESA SP-250, Vol. I, 347-352.

Eberhardt, P., Dolder, U., Schulte, W., Krankowsky, D., Lämmerzahl, P., Hoffman, J. H., Hodges, R. R., Berthelier, J. J., and Illiano, J. M. (1986b). The D/H ratio in water from Halley. Proc. 20th ESLAB Symposium on the Exploration of Halley's Comet, ESA SP-250, Vol. I, 539-541.

Eberhardt, P., Dolder, U., Schulte, W., Krankowsky, D., Lämmerzahl, P., Hoffman, J. H., Hodges, R. R., Berthelier, J. J., and Illiano, J. M. (1987b). The D/H ratio in water from Halley. Astron. Astrophy. 187, 435-437.

Eberhardt, P., Krankowsky, D., Schulte, W., Dolder, U., Lämmerzahl, P., Berthelier, J. J., Woweries, J., Stubbemannn, U., Hodges, R. R., Hoffman, J. H., and Illiano, J. M. (1986a). On the $\mathrm{CO}$ and $\mathrm{N}_{2}$ abundance in Comet Halley. Proc. 20th ESLAB Symposium on the Exploration of Halley's Comet, ESA SP-250, Vol. I, 383-386.

Eberhardt, P., Krankowsky, D., Schulte, W., Dolder, U., Lämmerzahl, P., Berthelier, J. J., Woweries, J., Stubbemannn, U., Hodges, R. R., Hoffman, J. H., and Illiano, J. M. (1987a). On the $\mathrm{CO}$ and $\mathrm{N}_{2}$ abundance in Comet Halley. Astron. Astrophys. 187, 481-484.

Encrenaz, T., d'Hendecourt, L., and Puget, J. L. (1988). On the interpretation of the 3.2-3.5 micron emission feature in the spectrum of Comet $\mathrm{P} / \mathrm{Halley}$ : Abundances in the comet and in interstellar space. Astron. Astrophys. 207, 162-173.

Fegley, B., Jr., and Prinn, R. G. (1989). Solar nebula chemistry: Implications for volatiles in the solar system. In The Formation and Evolution of Planetary Systems, eds. H. A. Weaver, F. Paresce, and L. Danly (Cambridge: Cambridge University Press), 171-212. 
Feldman, P. D. (1978). A model of carbon production in a cometary coma. Astr. Astrophys. 70, 547-553.

Feldman, P D. (1982). Ultraviolet spectroscopy of comae. In Comets, ed. Laurel L. Wilkening (Tucson: University of Arizona), 461-479.

Feldman, P. D. (1990). Ultraviolet spectroscopy of comets. (this book)

Feldman, P. D., A'Hearn, M. F., Festou, M. C., McFadden, L. A., Weaver, H. A., and Woods, T. N. (1986a). Is $\mathrm{CO}_{2}$ responsible for the outbursts of Comet Halley? Nature 324, 433-436.

Feldman, P. D., and Brune, W. H. (1976). Carbon production in Comet West (1975n). Astrophys. J. 209, L145-L148.

Feldman, P. D., Festou, M. C., A'Hearn, M. F., Arpigny, C., Butterworth, P. S., Cosmovici, C. B., Danks, A. C., Gilmozzi, R., Jackson, W. M., McFadden, L. A., Patriarchi, P., Schleicher, D. G., Tozzi, G. P., Wallis, M. K., Weaver, H. A., and Woods, T. N. (1986b). IUE observations of Comet Halley: Evolution of the UV spectrum between September 1985 and July 1986. Proc. 20th ESLAB Symposium on the Exploration of Halley's Comet, ESA SP-250, Vol. I, 325-328.

Feldman, P. D., Festou, M. C., A'Hearn, M. F., Arpigny, C., Butterworth, P. S., Cosmovici, C. B., Danks, A. C., Gilmozzi, R., Jackson, W. M., McFadden, L. A., Patriarchi, P., Schleicher, D. G., Tozzi, G. P., Wallis, M. K., Weaver, H. A., and Woods, T. N. (1987). IUE observations of Comet Halley: Evolution of the UV spectrum between September 1985 and July 1986. Astron. Astrophys. 187, 325-328.

Festou, M. C. (1981). The density distribution of of neutral compounds in cometary atmospheres. Astron. Astrophys. 95, 69-79.

Festou, M. C., Feldman, P. D., A'Hearn, M. F., Arpigny, C., Cosmovici, C. B., Danks, A. C., McFadden, L. A., Gilmozzi, R., Patriarchi, P., Tozzi, G. P., Wallis, M. K., and Weaver, H. A. (1986). IUE observations of Comet Halley during the VEGA and Giotto encounters. Nature 321, 361-363.

Festou, M. C., Feldman, P. D., and Weaver, H. A. (1982). The ultraviolet bands of the $\mathrm{CO}_{2}^{+}$ion in comets. Astrophys. J. 256, 331 .

Fowler, A. (1910). Investigations relating to the spectra of comets. Mon. Not. Roy. Astron. Soc. 70, 484-496.

Geiss, J. (1987). Composition measurements and the history of cometary matter. Astron. Astrophys. 187, 859-866.

Geiss, J. (1988). Composition in Halley's Comet: Clues to origin and history of cometary matter. In Reviews in Modern Astronomy, Vol. 1, ed. G. Klare (Berlin-Heidelberg: Springer), 1-27.

Greenberg, J. M. (1982). Laboratory dust experiments-tracing the composition of cometary dust. In Cometary Exploration, ed. T. I. Gombosi, Hungarian Acad. Sci. II, 23-54.

Greenberg, J. M., Grim, R., and van IJzendoorn, L. (1986). Interstellar $\mathrm{S}_{2}$ in comets. In Asteroids, Comets, Meteors II, eds. C.-I. Lagerkvist, B. A. Lindblad, H. Lundstedt, and H. Rickman (Uppsala: Uppsala University), 225-227.

Hanner, M. (1984). Comet Cernis: Icy grains at last? Astrophys. J. 277, L75.

Hartmann, W. K., and Cruikshank, D. P. (1983). Systematics of ices among remote comets, asteroids, and satellites. Bull. Amer. Astron. Soc. 15, 808 (abstract).

Haser, L. (1957). Distribution d'intensité dans la tête d'une comète. Bull. Acad. Roy. Belgique, Classe de Sciences 43, 740-750. 
Haser, L. (1966). Calcul de distribution d'intensité relatif dans une tête comètaire. Mém. Soc. Roy. Liège, Ser. 5, 12, 233-241.

Hollis, J. M., Brandt, J. C., Hobbs, R. W., Maran, S., and Feldman, P. D. (1981). Radio observations of Comet Bradfield (19791). Astrophys. J. 244, 355-357.

Huebner, W. F. (1987). First polymer in space identified in Comet Halley. Science, 237 628-630.

Huebner, W. F., and Carpenter, C. W. (1979). Solar Photo Rate Coefficients. Los Alamos Scientific Report No. LA-8085-MS.

Huebner, W. F., Snyder, L. E., and Buhl, D. (1974). HCN radio emission from Comet Kohoutek (1973f). Icarus 23, 580-584.

Iben, I., Jr. (1975). Thermal pulses; p-capture, s-process nucleosynthesis; and convecting mixing in a star of intermediate mass. Astrophys. J. 196, 525-547.

Ip, W.-H., Balsiger, H., Geiss, J., Goldstein, B. E., Kettmann, G., Lazarus, A., Meier, A. J., Rosenbauer, H., Schwenn, R., and Shelley, E. (1990). Giotto IMS measurements of the production rate of hydrogen cyanide in the coma of Comet Halley. Ann. Geophys. 8 , in press.

Jackson, W. M., Butterworth, P. S., and Ballard, D. (1986). The origin of CS in Comet IRAS-Araki-Alcock (1983d). Astrophys. J. 304, 515-518.

Jackson, W. M., Clark, T., and Donn, B. (1976). Radio detection of $\mathrm{H}_{2} \mathrm{O}$ in Comet Bradfield (1974b). In The Study of Comets, eds. B. Donn, M. Mumma, W. Jackson, M. A'Hearn, and R. Harrington (Washington: NASA SP-393), 272-280.

Jessberger, E. K. and Kissel, J. (1990). Chemical properties of cometary dust and and a note on carbon isotopes. (this book)

Kaneda, E., Ashihara, O., Shimizu, M., Takagi, M., and Hirao, K. (1986). Observation of Comet Halley by the ultraviolet imager of Suisei. Nature 321, 297-299.

Kawara, K., Gregory, B., Yamamoto, T., and Shibai, H. (1988). Infrared spectroscopic observation of methane in Comet P/Halley. Astron. Astrophys. 207, 174-181.

Kim, S. J., and A'Hearn, M. F. (1990). Sulfur compounds in comets. Icarus, in press.

Kim, S. J., A'Hearn, M. F., and Cochran, W. D. (1989). NH emissions in comets: Fluorescence vs. collisions. Icarus 77, 98-108.

Kissel, J., Brownlee, D. E., Büchler, K., Clark, B. C., Fechtig, H., Grün, E., Hornung, K., Igenbergs, E. B., Jessberger, E. K., Krueger, F. R., Kuczera, H., McDonnell, J. A. M., Morfill, G. M., Rahe, J., Schwehm, G. H., Sekanina, Z., Utterback, N. G., Völk, H. J., and Zook, H. A. (1986). Composition of Comet Halley dust particles from Giot to observations. Nature 321, 336-337.

Kitamura, Y. (1986). Axisymmetric dusty gas jets in the inner coma of a comet. Icarus 66, 241-257.

Kömle, N. I., and Ip, W.-H. (1986). Anisotropic non-stationary gas flow dynamics in the coma of Comet Halley. Proc. 20th ESLAB Symposium on the Exploration of Halley's Comet, ESA SP-250, Vol. I, 523-527.

Korth, A., Richter, A. K., Loidl, A., Anderson, K. A., Carlson, C. W., Curtis, D. W., Lin, R. P., Réme, H., Sauvaud, J. A., d'Uston, C., Cotin, F., Cros, A., and Mendis, D. A. (1986). Mass spectra of heavy ions near Comet Halley. Nature 321, 335-336.

Knacke, R. F., Brooke, T. Y., and Joyce, R. R. (1986). Observations of 3.2-3.6 micron emission features in Comet Halley. Astrophys. J. Lett. 310, L49-L53. 
Krankowsky, D., and Eberhardt, P. (1990). Evidence for the composition of ices in the nucleus of Comet Halley. In COMET HALLEY-Investigations, Results, and Interpretations, ed. J. Mason, Ellis Horwood Ltd., Chichester, England, 1990, in press.

Krankowsky, D., Eberhardt, P., Meier, R., Schulte, W., Lämmerzahl, P., and Hodges, R. R. (1990). Formaldehyde in Halley derived from Giotto NMS measurements. Astron. Astrophys., in preparation.

Krankowsky, D., Lämmerzahl, P., Herrwerth, I., Woweries, J., Eberhardt, P., Dolder, U., Herrmann, U., Schulte, W., Berthelier, J. J., Illiano, J. M., Hodges, R. R., and Hoffman, J. H. (1986). In situ gas and ion composition measurements at Comet Halley. Nature 321, 326-329.

Krasnopolsky, V. A., Gogoshev, M., Moreels, G., Moroz, V. I., Krysko, A. A., Gogosheva, Ts., Palazov, K., Sargoichev, S., Clairmidi, J., Vincent, M., Bertaux, J. L., Blamont, J. E., Troshin, V. S., and Valniček, B. (1986). Spectroscopic study of Comet Halley by the VEGA 2 three-channel spectrometer. Nature 321, 269-271.

Lacy, J. H., Baas, F., Allamandola, L. J., Persson, S. E., McGregor, P. J., Lonsdale, C. J., Geballe, T. R., and van de Bult, C. E. P. (1984). 4.6-micron absorption features due to solid phase $\mathrm{CO}$ and cyano group molecules toward compact infrared source. Astrophys. J. 276, 533-543.

Léger, A. (1983). Does CO condense on dust in molecular clouds? Astron. Astrophys. 123, 271-278.

Lewis, J. S. (1972). Low temperature condensation in the solar nebula. Icarus 16, 241-252.

Lewis, J. S., and Prinn, R. (1980). Kinetic inhibition of $\mathrm{CO}$ and $\mathrm{N}_{2}$ reduction in the solar nebula. Astrophys. J. 238, 357-364.

Lämmerzahl, P., Krankowsky, D., Hodges, R.R., Stubbemann, U., Woweries, J., Herrwerth, I., Bethelier, J. J., Tliano, J. M., Eberhardt, P., Dolder, U., Schulte, W., and Hoffman, J. H. (1987). Expansion velocity and temperature of gas and ions measured in the coma of Comet Halley. Astron. Astrophys. 187, 169-173.

Magee-Sauer, K., Scherb, F., Roesler, F. L., and Harlander, J. (1988). Fabry-Perot observations of $\mathrm{NH}_{2}$ emissions from Comet Halley. Bull. Am. Astron. Soc. 20(3), 827.

Magee-Sauer, K., Scherb, F., Roesler, F. L., Harlander, J., and Lutz, B. L. (1989). FabryPerot observations of the $\mathrm{NH}_{2}$ emission from Comet Halley. Icarus 82, 50-60.

Marconi, M. L., and Mendis, D. A. (1988). On the ammonia abundance in the coma of Halley's Comet. Astrophys. J. 330, 513-517.

Mazets, E. P., Aptekar, R. L., Golenetskii, S. V., Guryan, Yu. A., Dyachkov, A. V., Ilyinskii, V. N., Panov, V. N., Petrov, G. G., Savvin, A. V., Sagdeev, R. Z., Sokolov, I. A., Khavenson, N. G., Shapiro, V. D., and Shevchenko, V. I. (1986). Comet Halley dust environment from SP-2 detector measurements. Nature 321, 276-278.

McDonnell, J. A. M., Alexander, W. M., Burton, W. M., Bussoletti, E., Evans, G. C., Evans, S. T., Firth, J. G., Grard, R. J. L., Green, S. F., Grün, E., Hanner, M. S., Hughes, D. W., Igenbergs, E., Kissel, J., Kuczera, H., Lindblad, B. A., Langevin, Y., Mandeville, J.-C., Nappo, S., Pankiewicz, G. S. A., Perry, C. H., Schwehm, G. H., Sekanina, Z., Stevenson, T. J., Turner, R. F., Weishaupt, U., Wallis, M. K., and Zarnecki, J. C. (1987). The dust distribution within the inner coma of Comet P/Halley 1982i: Encounter by Giotto's impact detectors. Astron. Astrophys. 187, 719-741. 
Millis, R. L., and Schleicher, D. G. (1986). Rotational period of Comet Halley. Nature 324, 646-649.

Ming, T., Anders, E., Hoppe, P., and Zinner, E. (1989). Meteoritic silicon carbide and its stellar sources; Implications for galactic chemical evolution. Nature 339, 351-354.

Mitchell, D. L., Lin, R. P., Anderson, K. A., Carlson, C. W., Curtis, D. W., Korth, A., Richter, A. K., Réme, H., Sauvaud, J. A., d'Uston, C., and Mendis, D. A. (1986). Derivation of heavy (10-210 AMU) ion composition and flow parameters for the Giotto PICCA instrument. Proc. 20th ESLAB Symposium on the Exploration of Halley's Comet, ESA SP-250, Vol. I, 203-205.

Mitchell, D. L., Lin, R. P., Anderson, K. A., Carlson, C. W., Curtis, D. W., Korth, A., Réme, H., Sauvaud, J. A., d'Uston, C., and Mendis, D. A. (1987). Evidence for chain molecules enriched in carbon, hydrogen, and oxygen in Comet Halley. Science 237, 626-628.

Moroz, V. I., Combes, M., Bibring, J. P., Coron, N., Crovisier, J., Encrenaz, T., Crifo, J. F., Sanko, N., Grigoriev, A. V., Bockelée-Morvan, D., Gispert, R., Nikolsky, Yu. V., Emerich, C., Lamarre, J. M., Rocard, F., Krasnopolsky, V. A., and Owen, T. (1987). Detection of parent molecules in Comet Halley from the IKS-VEGA experiment. Astron. Astrophys. 187, 513-518.

Mumma, M. J., and Reuter, D. C. (1989). On the identification of formaldehyde in Halley's Comet. Astrophys. J. 344, 940-948.

Mumma, M. J., Weaver, H. A., Larson, H. P., Davis, D. S., and Williams, M. (1986). Detection of water vapor in Halley's Comet. Science 232, 1523-1528.

Prasad, S. S, and Huntress, W. T., Jr. (1980). A model for gas phase chemistry in interstellar clouds: I. The basic model, library of chemical reactions, and chemistry among C, N, and O compounds. Astrophys. J. Suppl. 43, 1-35.

Prialnik, D., and Bar-Nun, A. (1987). On the evolution and activity of cometary nuclei. Astrophys. J. 313, 893-905.

Prinn, R. G., and Fegley, B., Jr. (1989). Solar nebula chemistry: Origin of planetary, satellite, and cometary volatiles. In Planetary and Satellite Atmospheres: Origin and Evolution (Tucson: University of Arizona Press), 78-136.

Sagdeev, R. Z., Evlanov, M. N., Fomenkova, M. N., Prilutskii, O. F., and Zubkov, B. V. (1989). Small-size dust particles near Halley's Comet. Adv. Space Res. 9(3), 263-267.

Schleicher, D. G., A'Hearn, M. F., and the NASA and ESA IUE teams for comet Halley (1986). Comets $\mathrm{P} / \mathrm{Halley}$ and $\mathrm{P} /$ Giacobini-Zinner at high dispersion. Proc. IUE conference (London).

Schloerb, F. P., Kinzel, W. M., Swade, D. A., and Irvine, W. M. (1986). HCN production from Comet Halley. Astrophys. J. 310, L55-L60.

Schloerb, F. P., Kinzel, W. M., Swade, D. A., and Irvine, W. M. (1987). Observations of HCN in Comet P/Halley. Astron. Astrophys. 187, 475-480.

Smith, A. M., Stecher, T. P., and Casswell, L. (1980). Production of carbon, sulfur and CS in Comet West. Astrophys. J. 242, 402-410.

Snyder, L. E., Buhl, D., Zuckerman, B., and Palmer, P. (1969). Microwave detection of interstellar formaldehyde. Phys. Rev. Lett. 22, 679-681.

Snyder, L. E., Palmer, P., and de Pater, I. (1989). Radio detection of formaldehyde emission from Comet Halley. Astron. J. 97(1), 246-253.

Snyder, L. E., Palmer, P., and de Pater, I. (1990). Observation of formaldehyde in Comet Machholz $1988 \mathrm{j}$. Icarus, in press. 
Stewart, A. I. F. (1987). Pioneer Venus measurements of H, O, and C production in Comet $\mathrm{P} /$ Halley near perihelion. Astron. Astrophys. 187, 369-374.

Swings, P., and Page, T. L. (1948). The spectrum of Comet (1947n). Astrophys. J. 108, 526-536.

Tegler, S., and Wyckoff, S. (1989). $\mathrm{NH}_{2}$ fluorescence efficiencies and the $\mathrm{NH}_{3}$ abundance in Comet Halley. Astrophys. J. 343, 445-449.

Ulich, B. L., and Conklin, E. J. (1974). Detection of methyl cyanide in Comet Kohoutek. Nature 248, 121-122.

Vaisberg, O., Smirnov, V., and Omelchenko, A. (1986). Spatial distribution of low-mass dust particles $\left(\mathrm{m}<10^{-10} \mathrm{~g}\right)$ in Comet Halley coma. Proc. 20th ESLAB Symposium on the Exploration of Halley's Comet, ESA SP-250, Vol. II, 17-23.

Wallis, M. K., and Krishna Swamy, K. S. (1987). Some diatomic molecules from Comet P/Halley's UV spectra near spacecraft flybys. Astron. Astrophys. 187, 329-332.

Weaver, H. A. (1981). Ultraviolet spectra of comets observed with the International Ultraviolet Explorer satellite. Ph.D. thesis, John Hopkins University.

Weaver, H. A., Mumma, M. J., Larson, H. P., and Davis, D. S. (1986). Airborne infrared investigation of water in the coma of Halley's Comet. Proc. 20th ESLAB Symposium on the Exploration of Halley's Comet, ESA SP-250, Vol. I, 329-334.

Weaver, H. A., Mumma, M. J., and Larson, H. P. (1990). Infrared spectroscopy of cometary parent molecules. (this book)

Whipple, F. L. (1989). Comets in the space age. Astrophys. J. 341, 1-15.

Winnberg, A., Ekelund, L., and Ekelund, A. (1987). Detection of HCN in Comet P/Halley. Astron. Astrophys. 172, 335-341.

Woods, T. N., Feldman, P. D., Dymond, K. F., and Sahnow, D. J. (1986). Rocket ultraviolet spectroscopy of Comet Halley and abundance of carbon monoxide and carbon. Nature 324, 436-438.

Wopenka, B., Virag, A., Zinner, E., Amari, S., Lewis, R. S., and Anders, E. (1989). Isotopic and optical properties of large individual silicon carbide crystals from the Murchison chondrite. Meteoritics 24, 342.

Wrickramasinghe, D. T., and Allen, D. A. (1986). Discovery of organic grains in Comet Halley. Nature 323, 44-46.

Wurm, K. (1943). Die Natur der Kometen. Mitt. Ham. Sternwarte 8, No. 51.

Wyckoff, S., Lindholm, E., Wehinger, P. A., Peterson, B. A., Zucconi, J.-M., and Festou, M. C. (1989a). The ${ }^{12} \mathrm{C} /{ }^{13} \mathrm{C}$ abundance ratio in Comet Halley. Astrophys. J. 339, 488-500.

Wyckoff, S., Tegler, S., Wehinger, P. A., Spinrad, H., and Belton M. J. S. (1988). Abundances in Comet Halley at the time of the spacecraft encounters. Astrophys. J. 325, 927-938.

Wyckoff, S., Tegler, S., and Engel, L. (1989b). Ammonia abundances in comets. Adv. Space Res. $\mathbf{8}(3), 169-176$.

Wyckoff, S., and Theobald, J. (1989). Molecular ions in comets. Adv. Space Res. 9(3), $157-161$.

Wyckoff, S., and Wehinger, P. A. (1976). Molecular ions in comet tails. Astrophys. J. 204, 604-615.

Yamamoto, T., Nakagawa, N., and Fukui, Y. (1983). The chemical composition and thermal history of the ices of a cometary nucleus. Astron. Astrophys. 122, 171-176. 
Zinner, E., Tang, M., and Anders, E. (1989). Interstellar SiC in the Murchison and Murray meteorites: Isotopic composition of $\mathrm{Ne}, \mathrm{Xe}, \mathrm{Si}, \mathrm{C}$, and N. Geochim. Cosmochim. Acta 53, 3273-3290.

Zinner, E., and Wopenka, B. (1990). Interstellar graphite and other carbonaceous grains from the Murchison meteorite: Structure, composition, and isotopes of $\mathrm{C}, \mathrm{N}$, and Ne. Lunar and Planet. Sci. XXI (Houston: Lunar and Planetary Institute), 1379 (abstract). 